Stream: Culture/Politics/Technology, 6(1): 1-2

http://journals.sfu.ca/cpt/index.php/stream/index

\title{
Introduction: The Legacy of Graham Spry and the Future of Public Media
}

\section{Sibo Chen}

School of Communication, Simon Fraser University

Over the past twenty years, public media services worldwide have been facing increasing pressure from commercialization, marketization, and privatization. This situation is exemplified by the Canadian Broadcasting Corporation's (CBC) latest revenue shortfall and the subsequent austerity measures of the corporation. Indeed, $\mathrm{CBC}$, as an iconic corporation of Canadian's media landscape, is key to the country's future policy-making in the media realm. The CBC's current crisis, already exerting significant pressures towards the restructuring of the corporation, is seen by some critics as a warning of the corporation's potential imminent collapse (Rowland, 2013). However, just as there has be a constant pressure toward marketization over public media, over the past few years the struggles of public media also offer a precious opportunity to re-imagine an alternative future for public communication services.

To some extent, the exploration of alternative future requires us to look back, reclaiming the significance of the forgotten part of our history. As McChesney (1999) argued in more than one decade ago: "To get public broadcasting back on course, it is necessary to take a page from Graham Spry and the other pioneers of public broadcasting in Canada, the United States, and elsewhere, and see it as a necessary democratic agency" (p. 45). If we want to discuss an alternative future of public media in Canada, we have to review the arguments and activities of Graham Spry, as well as his significant contributions to the development of broadcasting in North America.

Born in St. Thomas, Ontario, Graham Spry was a business executive, diplomat, socialist, and most importantly, broadcasting pioneer. Along with Alan Plaunt, Spry founded the Canadian Radio League and rallied support behind the Aird Commission's recommandations, which eventually convinced the Conservative government of R.B. Bennett to form the Canadian Radio Broadcasting Commission, precursor to the Canadian Broadcasting Corporation as we know it today. The core belief behind Spry's dedication to public broadcasting is a belief in creating the conditions for communication in the public good (Raboy, 2006). As Spry himself argues:

"Let the air remain as the prerogative of commercial interests and subject to commercial control, and how free will be the voice, the heart of democracy. The maintenance, the enlargement of freedom, the progress, the purity of education, require the responsibility of broadcasting to the popular will. There can be no liberty complete, no democracy supreme, if the commercial interests dominate the vast, majestic resource of broadcasting" (Spry, 1931, pp. 57-58).

This special issue of Stream aims to reflect some of the latest trends in the re-imagination of public media. Following the legacy of Graham Spry, this issue hopes to offer a variety of perspectives on the alternative futures of CBC and other public media services.

The opening piece, in which Mike Mowbray interviews Wade Rowland, addresses the acute dilemmas of CBC and possible directions forward. Rowland's recent book Saving the CBC: Balancing Profit and Public Service has stimulated a heated discussion in the public realm and in the opening paper's featured interview he offers some key reflections on the possible futures of public media in Canada.

By documenting the CRTC's de-regulation of Canadian Television, Zoë Druick argues that entrepreneurialism has become the dominant logic of Canadian media landscape, which is in turn subordinated to the profit-making purposes of large media conglomerates. Following Druick's piece, Frederik Lesage discusses the technological imagination of public media and why the future of digital infrastructure is crucial for the future of public media. 
The next three papers document pioneer efforts in the exploration of public media's new forms. Tara Mahoney analyzes "Reimagine CBC" and demonstrates how fostering a culture of open innovation could provide effective strategies for civic engagement in public media. Focusing on digital practices during the "Maple Spring" in Québec, Claude Fortin offers a convincing analysis of the expansion of alternative press via grassroots networks and the potential for alternative public media forms. In line with Fortin, Amanda Oye reviews the significance and value of publicly funding journalism, arguing that a non-profit public model focused on the production of quality news retains its relevance as key to the CBC's mandate and future potential.

It is important to emphasize that the discussion of public media should not be limited to Canada or the Global North. Globalization, along with its inherent market logic, also generates significant impacts on public media services in the Global South. Using Bangladesh as a revealing case, Anis Rahman analyzes the development of public media infrastructure and services in this country, and how these issues are influenced by the country's unique nation-state dynamics.

As Raboy (2006) concludes in the 2005 Graham Spry Memorial Lecture: "a new and burgeoning global communication rights movement is making incursions in venues (p. 306)". We hope this special issue reflects the legacy of Graham Spry and invite you to join the discussion of public media's future.

\section{Acknowledgement}

The Stream editorial team would like to thank Spry Foundation for its support of this special issue. We would like to thank all of our contributors for sharing their work through the open-access format as well as all of our reviewers for their hard work.

\section{References}

McChesney, R. W. (1999). Graham spry and the future of public broadcasting. Canadian Journal of Communication, 24(1), 25-47.

Raboy, M. (2006). The 2005 graham spry memorial lecture making media: Creating the conditions for communication in the public good. Canadian Journal of Communication, 31(2), 289-306.

Rowland, W. (2013). Saving the CBC: Balancing profit and public service. Westmount, QC: Linda Leith Publishing.

Spry, G. (1931). The Canadian radio situation. In J. H. Maclatchy (Ed.), Education on the air, (pp. 4760). Second Yearbook of the Institute for Education by Radio. Columbus, OH: Ohio State University Press. 